\title{
Hot flashes in breast cancer survivors and an association with calcium supplement use
}

This article was published in the following Dove Press journal:

International Journal of Women's Health

2I August 2010

Number of times this article has been viewed

\section{Gretchen Kimmick ${ }^{1,2}$ \\ Gloria Broadwater ${ }^{2}$ \\ Mara Vitolins ${ }^{3}$}

'Medical Oncology, Wake Forest University School of Medicine,

Winston-Salem; ${ }^{2}$ Cancer Center

Biostatistics, Duke University Medical

Center, Durham; ${ }^{3}$ Department of Epidemiology and Prevention, Wake

Forest University School of Medicine,

Winston-Salem, North Carolina, USA
Aims: In breast cancer survivors, we aimed to describe the frequency of hot flashes and night sweats, frequency and type of treatment, and the association of hot flashes and use of calcium supplements.

Methods: Charts of breast cancer survivors were reviewed for information about hot flashes, treatment for hot flashes, and calcium supplementation. Associations between variables were explored using the Chi-square test and Fisher's Exact test.

Results: Eighty-six charts were reviewed. Mean age of the women was 58 years and $79 \%$ were postmenopausal. Forty-two (49\%) of women had hot flashes and 18 (21\%) had night sweats. Thirty-one (36\%) were treated for hot flashes. Treatment included selective serotonin reuptake inhibitors/serotonin-norepinephrine reuptake inhibitors $(n=19)$, clonidine $(n=7)$, Bellergal- $S^{\circledR}$ $(\mathrm{n}=8)$, sleep-aid $(\mathrm{n}=7)$, and other $(\mathrm{n}=5)$. Calcium supplementation was recorded in $31 \%$. Of women with hot flashes, $44 \%$ took calcium supplements; of women without hot flashes, $18 \%$ took calcium supplements (Chi-square $P=0.02$ ).

Conclusion: Hot flashes were recorded in $49 \%$ of this group of primarily postmenopausal breast cancer survivors. Women with hot flashes were more likely to be taking calcium supplements. Further exploration of the association between hot flashes and calcium supplementation is warranted.

Keywords: hot flashes, breast cancer, calcium supplementation

\section{Introduction}

Hot flashes are bothersome and sometimes life-disrupting in breast cancer survivors. Estrogen-based therapies decrease hot flashes by up to $90 \%$, but their use is generally discouraged in breast cancer survivors and in women with an increased risk of breast cancer. ${ }^{1-3}$

Several hormonal and nonhormonal therapies are claimed to alleviate hot flashes. These include hormonal agents, such as progestational agents, complementary and alternative therapies and supplements, and pharmacologic agents. Hormonal therapies seem to be most effective, but women at risk for or who have survived breast cancer may carry an increased risk of new or relapsed cancer. ${ }^{4}$ As such, studies have aimed to find nonhormonal agents that can decrease this bothersome symptom. Many therapies have been studied, but none seem to be as effective as hormonal therapies. ${ }^{5}$ Other commonly prescribed nonhormonal treatments for hot flashes are well described in a recent review, ${ }^{6}$ and include selective serotonin reuptake inhibitors (SSRIs), serotonin norepinephrine reuptake inhibitors (SNRIs), clonidine, gabapentin, and others. 
Many women take prescription and over-the-counter medication for treatment of hot flashes. There is sparse information about what women are actually taking. In a population of breast cancer patients, we aimed to describe the frequency of hot flashes and night sweats, list what treatments were employed, and explore the possible association of hot flashes and use of calcium supplements.

\section{Methods}

We retrospectively reviewed clinic charts of a randomly selected sample of women with breast cancer treated at a single institution. Cases were randomly selected for inclusion by arranging all breast cancer cases in alphabetical order and then choosing every fourth chart for review. The study was approved by the Institutional Review Board at Wake Forest University School of Medicine.

Information gathered included the following: demographic information including age at diagnosis and race; adjuvant

Table I Patient characteristics

\begin{tabular}{ll}
\hline Age at diagnosis, mean (range) & $58(29-92)$ \\
Menopausal status, $\mathrm{n}(\%)$ & $9(\mathrm{II})$ \\
Pre & $8(10)$ \\
Peri & $65(79)$ \\
Post & \\
Race, $\mathrm{n}(\%)$ & $62(84)$ \\
White & $12(16)$ \\
Nonwhite & $63.5(58-71) \mathrm{cm}$ \\
Height, median (range) & $72.6(45.4-117.9) \mathrm{kg}$ \\
Weight, median (range) & \\
Tumor size, $\mathrm{n}$ (\%) & $35(48)$ \\
TI & $30(42)$ \\
T2 & $5(7)$ \\
T3 & $2(3)$ \\
T4b & \\
Nodal status, $\mathrm{n}$ (\%) & $39(54)$ \\
Negative & $3 \mathrm{I}(43)$ \\
Positive & $2(3)$ \\
Unknown & 8 \\
Metastatic disease, $\mathrm{n}$ & $21(49)$ \\
ER status & \\
Positive & $53(80)$ \\
Negative & $13(20)$ \\
Positive & \\
Hegatus & $42(68)$ \\
Negative & \\
\hline
\end{tabular}

hormonal therapy use for breast cancer, defined as any record in the chart for prescription of tamoxifen or an aromatase inhibitor; menopausal status as recorded in clinician notes; presence or absence of hot flashes and/or night sweats as recorded in the chart; prescribed treatment for hot flashes as indicated in the clinical records; and any record of calcium supplementation in the medication list, although the exact amount of calcium per day and additional use of vitamin D was not available in most charts.

Descriptive statistics were used to describe variables. To explore the associations between variables, the Chi-square test and Fisher's Exact tests were used for variables with larger and smaller sample sizes, respectively.

\section{Results}

There were 86 charts reviewed (Table 1). Menopausal status was post- in $79 \%$, peri- in $10 \%$, and pre- in $11 \%$. A record of hot flashes was found in 42 (49\%) charts and a record of night-time hot flashes was found in 18 (21\% of the total and $43 \%$ of those with hot flashes) charts (Table 2). Hot flashes were reported as life-disrupting in $17 \%$ of charts reviewed.

There was no statistically significant association between presence of hot flashes and antihormonal therapy; $42 \%$ of women not taking antihormonal therapy reported hot flashes versus $59 \%$ on antihormonal therapy $(P=0.13)$.

Treatment for hot flashes was recorded in 31 (36\%) of the 86 charts. Treatments for hot flashes included SSRIs/SNRIs $(\mathrm{n}=19)$, clonidine $(\mathrm{n}=7)$, Bellergal-S ${ }^{\circledR}(\mathrm{n}=8)$, sleep-aid $(n=7)$, and others $(n=5)$.

Calcium supplementation was recorded in $31 \%$ of records. Interestingly, we found an association between hot flashes and calcium supplementation. Of women with hot flashes, 44\% took calcium supplements and 56\% did not; of women without hot flashes, $18 \%$ took calcium supplements and $82 \%$ did not (Chi-square $P=0.02$ ) (Table 3 ).

\section{Discussion}

Hot flashes were recorded in half of this group of primarily postmenopausal breast cancer survivors. Among women with hot flashes, almost half also complained of night sweats. These figures are similar to what has been reported in a

Table 2 Finding complaint of hot flashes, night sweats, and indication that hot flashes were life-disrupting in the medical record

\begin{tabular}{ll}
\hline & $\mathrm{n}(\%)$ \\
\hline Hot flashes & $42(48)$ \\
Night sweats & $18(21)$ \\
Life-disrupting hot flashes & $14(17)$ \\
\hline
\end{tabular}


Table 3 Association between hot flashes and calcium supplementation

\begin{tabular}{llll}
\hline & \multicolumn{3}{l}{ Calcium supplement } \\
\cline { 2 - 4 } & No & Yes \\
\hline Hot flashes & 31 & 7 & 38 \\
No & 19 & 15 & 34 \\
Yes & 50 & 22 &
\end{tabular}

Chi-square $P=0.02$.

review of the world literature on prevalence of hot flashes and night sweats.?

We found no relationship between use of antihormonal therapy and occurrence of hot flashes. In contrast, clinical trials and other studies find that menopausal symptoms are more common in breast cancer patients versus controls and in patients taking antihormonal therapy versus not. ${ }^{7-12}$ There are several possible explanations for the lack of an effect of antihormonal therapy on occurrence of hot flashes in our analysis. First, there may have been a lack of recorded information about hot flashes in the medical records, but at this particular institution, there were ongoing studies for women with hot flashes and inquiry about the symptom was common. Second, the study population, although randomly selected from an existing group, may not be representative of the group or of the population of breast cancer survivors as a whole. Third, the study may have lacked the power to find a difference. Alternatively, the finding may be real in this population of primarily postmenopausal women, whose hot flash level may not have been as significantly affected by the addition of adjuvant hormonal therapy.

In this sample of breast cancer survivors, record of a treatment for hot flashes was found in $36 \%$ of charts. This is lower than found in a survey of a family practice, where almost $70 \%$ of postmenopausal women with moderate-tosevere hot flashes said they would want an intervention, with a desired hot flash reduction of at least $50 \%{ }^{13}$

Breast cancer survivors in this study were taking a variety of treatments to manage symptoms of hot flashes. These included SSRIs/SNRIs, clonidine, Bellergal-S, sleep-aid, and others. None of the charts reviewed recorded use of estrogen or herbal supplements to manage hot flashes. This is in line with therapies that have been proven helpful and safe in managing hot flashes in breast cancer survivors. ${ }^{6}$ In a systematic review and meta-analysis of data on nonhormonal therapies for menopausal hot flashes, compared with placebo, the number of daily hot flashes decreased with SSRIs or SNRIs (mean difference $-1.13 ; 95 \%$ confidence interval $[\mathrm{CI}]-1.70$ to -0.57 ), clonidine $(-0.95 ; 95 \% \mathrm{CI}-1.44$ to -0.47$)$, and gabapentin $(-2.05 ; 95 \% \mathrm{CI}-2.80$ to -1.30$){ }^{5}$ This chart review took place in 2003, before gabapentin and pregabalin had been shown to be helpful for treatment of hot flashes. ${ }^{14-16}$ In a case-control study of 73 breast cancer survivors, $29 \%$ reported use of nonestrogen therapy specifically for treatment of menopausal symptoms. ${ }^{12}$ In their study, which was published perhaps before widespread acceptance of the value of SSRIs/SNRIs for alleviation of hot flashes, the most commonly reported nonestrogen treatments were deliberate increase in either dietary or supplemental soy products, vitamin E, other herbal preparations, clonidine, vitamin B6, and other miscellaneous therapies. Antidepressants, including tricyclic antidepressants (used in $2 / 73$ cases) and venlafaxine (used in $1 / 73$ cases), were among the miscellaneous therapies.

Having observed reports that calcium might alleviate symptoms of premenstrual syndrome, ${ }^{17,18}$ we were interested to explore the possibility that calcium supplements might alleviate hot flashes. Interestingly, we found an association between calcium supplementation and hot flashes, but it was not in the direction that we had hypothesized. Women whose records indicated use of calcium supplements were more likely to report hot flashes than those not using calcium. One possible explanation for this could be as simple as the fact that women with lower estrogen levels, and thereby more hot flashes, have lower bone mass and are more frequently told to take calcium supplements. In other words, we may simply find more hot flashes in women who take calcium because of low estrogen levels. Another potential explanation is that some women were taking calcium supplements to treat hot flashes, but we did not find this was the case from the records reviewed. However, this was a retrospective study, and we realize that we may not be able to detect when a patient independently decided to take calcium supplements to treat hot flashes and, if this particular therapeutic strategy was of low efficacy, we would detect a higher level of hot flashes in these women.

Alternatively, calcium intake may induce production of hormones that increase hot flashes. A plausible endocrinologic explanation for calcium's relationship with hot flashes is through calcitonin gene-related peptide (CGRP). Calcium stimulates secretion of two peptides, ie, calcitonin, a hormone that functions to reduce blood calcium levels by increasing renal calcium excretion and decreasing release of calcium from bone, and CGRP, a neuropeptide that may be important in vasomotor-related symptoms. CGRP is a potent vasodilator neuropeptide and has been shown to be closely related to the occurrence of menopausal hot flashes. ${ }^{19-22}$ In addition, CGRP is high in postmenopausal women with hot flashes 
and decreases after successful treatment. ${ }^{23,24}$ Although a causal explanation for the increased reports of hot flashes in women also taking calcium cannot be made from this study, further exploration of the association between hot flashes and calcium supplementation is warranted.

\section{Conclusion}

In summary, complaints of hot flashes were found in the records of approximately half of these breast cancer survivors and were life-disrupting in $17 \%$. Half of those with hot flashes also complained of night sweats. A variety of medications were used for hot flashes, including those that were considered effective at the time. Calcium supplementation does not appear to alleviate hot flashes. In fact, we found an association between calcium supplementation and hot flashes, such that women taking calcium supplements were more likely to report hot flashes. Because the combination of calcium and vitamin $\mathrm{D}$ is recommended for good bone health, the relationship of this combined supplementation and hot flashes warrants exploration.

\section{Disclosure}

The authors report no conflict of interest in this work.

\section{References}

1. Nelson HD. Commonly used types of postmenopausal estrogen for treatment of hot flashes: Scientific review. JAMA. 2004;291(13):1610-1620.

2. von Schoultz E, Rutqvist LE. Menopausal hormone therapy after breast cancer: The Stockholm randomized trial. J Natl Canc Inst. 2005; 97(7):533-535.

3. Lyytinen H, Pukkala E, Ylikorkala O. Breast cancer risk in postmenopausal women using estrogen-only therapy. Obstet Gynecol. 2006; 108(6):1354-1360.

4. Fabre A, Fournier A, Mesrine S, et al. Oral progestagens before menopause and breast cancer risk. Br J Cancer. 2007;96(5):841-844.

5. Nelson HD, Vesco KK, Haney E, et al. Nonhormonal therapies for menopausal hot flashes: Systematic review and meta-analysis. JAMA. 2006;295(17):2057-2071.

6. Pachman DR, Jones JM, Loprinzi CL. Management of menopauseassociated vasomotor symptoms: Current treatment options, challenges, and future directions. Int J Women's Health. 2010;2:123-135.

7. Freeman EW, Sherif K. Prevalence of hot flushes and night sweats around the world: A systematic review. Climacteric. 2007;10(3):197-214.

8. Land SR, Wickerham DL, Costantino JP, et al. Patient-reported symptoms and quality of life during treatment with tamoxifen or raloxifene for breast cancer prevention: The NSABP Study of Tamoxifen and Raloxifene (STAR) P-2 trial. JAMA. 2006;295(23):2742-2751.
9. Jones SE, Cantrell J, Vukelja S, et al. Comparison of menopausal symptoms during the first year of adjuvant therapy with either exemestane or tamoxifen in early breast cancer: Report of a Tamoxifen Exemestane Adjuvant Multicenter trial substudy. J Clin Oncol. 2007; 25(30):4765-4771.

10. Fallowfield L, Cella D, Cuzick J, et al. Quality of life of postmenopausal women in the Arimidex, Tamoxifen, Alone or in Combination (ATAC) Adjuvant Breast Cancer Trial. J Clin Oncol. 2004;22(21):4261-4271.

11. Whelan TJ, Goss PE, Ingle JN, et al. Assessment of quality of life in MA.17: A randomized, placebo-controlled trial of letrozole after 5 years of tamoxifen in postmenopausal women. J Clin Oncol. 2005;23(28):6931-6940.

12. Harris PF, Remington PL, Trentham-Dietz A, et al. Prevalence and treatment of menopausal symptoms among breast cancer survivors. J Pain Symptom Manage. 2002;23(6):501-509.

13. Butt DA, Deng LY, Lewis JE, et al. Minimal decrease in hot flashes desired by postmenopausal women in family practice. Menopause. 2007;14(2):203-207.

14. Loprinzi CL, Dueck AC, Khoyratty BS, et al. A phase III randomized, double-blind, placebo-controlled trial of gabapentin in the management of hot flashes in men (N00CB). Ann Oncol. 2009;20(3):542-549.

15. Loprinzi CL, Sloan J, Stearns V, et al. Newer antidepressants and gabapentin for hot flashes: An individual patient pooled analysis. J Clin Oncol. 2009;27(17):2831-2837.

16. Loprinzi CL, Qin R, Stella PJ, et al. Pregabalin for hot flashes in women: NCCTG trial N07C1. 2009 ASCO annual meeting proceedings. J Clin Oncol. 2009;27(15S):9513.

17. Thys-Jacobs S, Starkey P, Bernstein D, et al. Calcium carbonate and the premenstrual syndrome: Effects on premenstrual and menstrual symptoms. Premenstrual Syndrome Study Group. Am J Obstet Gynecol. 1998;179(2):444-452.

18. Bertone-Johnson ER, Chen WY, Holick MF, et al. Plasma 25hydroxyvitamin D and 1,25-dihydroxyvitamin D and risk of breast cancer. Cancer Epidemiol Biomarkers Prev. 2005;14(8):1991-1997.

19. Chen JT, Hirai Y, Seimiya Y, et al. Menopausal flushes and calcitonin-gene-related peptide. Lancet. 1993;342(8862):49.

20. Valentini A, Petraglia F, De Vita D, et al. Changes of plasma calcitonin gene-related peptide levels in postmenopausal women. Am J Obstet Gynecol. 1996;175(3 Pt 1):638-642.

21. Wyon YA, Spetz AC, Theodorsson GE, et al. Concentrations of calcitonin gene-related peptide and neuropeptide $\mathrm{Y}$ in plasma increase during flushes in postmenopausal women. Menopause. 2000;7(1):25-30.

22. Wyon Y, Frisk J, Lundeberg T, et al. Postmenopausal women with vasomotor symptoms have increased urinary excretion of calcitonin gene-related peptide. Maturitas. 1998;30(3):289-294.

23. Wyon Y, Lindgren R, Lundeberg T, et al. Effects of acupuncture on climacteric vasomotor symptoms, quality of life and urinary excretion of neuropeptides among postmenopausal women. Menopause. 1995; 2:3-12.

24. Chen JT, Shiraki M. Menopausal hot flash and calciotonin gene-related peptide; effect of Keishi-bukuryo-gan, a kampo medicine, related to plasma calciotonin gene-related peptide level. Maturitas. 2003; 45(3):199-204.
International Journal of Women's Health

\section{Publish your work in this journal}

The International Journal of Women's Health is an international, peerreviewed open-access journal publishing original research, reports, reviews and commentaries on all aspects of women's healthcare including gynecology, obstetrics, and breast cancer. Subject areas include: Chronic conditions (migraine headaches, arthritis, osteoporosis);

\section{Dovepress}

Endocrine and autoimmune syndromes; Sexual and reproductive health; Psychological and psychosocial conditions. The manuscript management system is completely online and includes a very quick and fair peer-review system. Visit http://www.dovepress.com/ testimonials.php to read real quotes from published authors. 